\title{
Die bejahende Antwort in den obugrischen Sprachen
}

Das Wissen und die Erfahrung der Menschheit vererbt sich heutzutage hauptsächlich durch das Studium und durch Bücher auf die folgende Generation. Beror es die Bücher gab, konnte man neue Erfahrungen und Kenntnisse boinahe ausschliesslich durch Fragen erhalten. Die Jüngeren und Lnerfahreneren stellten den Älteren Fragen und bereicherten somit ihr Wissen. Auch heute fragen die Kinder, bevor sie zur Schule kommen, die um Jahre Älteren alle möglichen Dinge; sie wollen die Welt verstehen, in der sie leben, sowie ihre Erscheinungen, die sie noch nicht zur Genüge kennen.

Eine Frage kann eine Ergänzung oder eine Entscheidung verlangen. Hat der Fragende eine unklare Vorstellung von irgendeiner Angelegenheit oder irgendeinem Geschehen, und wenn ihm ein wichtiger Umstand unbekannt ist, so fragt er, was geschehen ist, wer dies oder jenes getan hat, wo es passierte, wie es ausgegangen ist, welcher Art dies oder jenes war. Ist der Gesprächspartner zu einer Antwort geneigt und kennt er die Dinge besser, ergänzt er die Kenntnis des Fragenden. Man kann mit einem vollständigen Satz antworten oder in der Form, dass die Antwort nur den erfragten Lmstand enthält. Z.B. Mihin matkustat? (Wohin reist du?) - Matkustan Turkuun (Ich reise nach Turku) oder einfacher: Turkuun (nach Turku), denn das ist es ja gerade, was dem Fragenden unbekannt ist. Wenn der Antwortende beim Fragen mit seinen Gedanken woanders ist und nicht gleich begreift, worum es sich handelt, oder wenn die Frage zı befremdlich und unerwartet kommt, kann er sie automatisch wiederholen. Er verschafft sich somit einen Augenblick Bedenkzeit. Die Frage: Mihin matkustat? kann somit auch beantwortet werden: Mihin 
minä matkustan? |Tietysti| Turkuun (Wohin ich reise? [Natürlich| nach Turku) oder Mihin? Minä matkustan Turkuun (Wohin? Ich reise nach Turku) usw.

Wenn der Antwortende die Kenntnis des Fragenden nicht ergänzen kann oder will, so sagt er: En tiedä (Ich weiss es nicht) oder er gibt eine ausweichende Antwort. Auch damn kann er die Frage wiederholen.

Hat der Fragende bereits eine Vorstellung von eimer Angelegenheit oder einem Ereignis und weiss aber nicht, ob sie richtig oder falsch ist, erwartet er von dem Antwortenden eine positive oder negative Entscheidung. Z.B. Onko Tampere Turkua suurempi? (Ist Tampere grösser als Turku?) Das gleiche lässt sich auch mit folgenden Worten fragen: Eikö Tampere ole suurempi kuin Turku? (Ist Tampere nicht grösser als 'Turku?) oder' Onko Tampere suurempi vai pienempi kuin Turku? (Ist Tampere grüsser oder kleiner als Turku?) Der gleiche Umstand kann auch in Form einer Ergänzungsfrage erfragt werden: Kumpi on suurempi: Turku vai Tampere? (Welche Stadt ist grüsser: 'Turku oder Tampere?)

Wenn eine Entscheidungsfrage gestellt wird, kann die Antwort bejahend, verneinend, bedingend oder ausweichend ausfallen. Oft mag es auch vorkommen, dass man mit En tiedä (Ich weiss nicht) oder ähnlich zu antworten hat.

Nicht nur auf eine Frage kann geantwortet werden. Häufig antwortet man auch auf eine Aufforderung, auf einen Befehl. Gehorcht der Aufgeforderte, crübrigt sich eine Antwort im allgemeinen, wenn er sich jedoch weigert, bringt er dies gewöhnlich durch eine negative Antwort zum Ausdruck. Z.B. Tule kanssamme käcelemään! (Komm mit uns spazieren!) Die bejahende Antwort kann lauten Tulen kyllä (Ja, ich komme), die verneinende $E n$ tule (Ich komme nicht) oder En voi tulla (Ich kann nicht kommen) udgl.

Oft wird auch dann geantwortet, wenn keine direkte Frage und auch keine Aufforderung vorliegt. Wenn jemand etwas berichtet, verkündet oder initteilt, kann der andere spontan seine Zustimmung ausdrücken. Wenn etwas sehr ausführlich und langwierig erzählt wird, will der Zuhörer oft zeigen, dass er alles versteht und genau zuhört. Aus diesem Grund äussert er sich des öfteren beifällig. 
Im folgenden möchte ich darstellen, mit welchen Mitteln eine bejahende Antwort auf Entscheidungsfragen oder Aufforderungen in den obugrischen Sprachen ausgedrückt wird. In den heutigen indoeuropäischen Sprachen ist die positive Antwort sehr einfach: im Schwedischen sagt man $j a$ oder $j o$, im Deutschen ja, im Englischen yes, im Französischen oui, im Italienischen und Spanischen si, im Russischen da, im Tschechischen ano usw.

Auch in den indoeuropäischen sprachen ist die bejahende Partikel relativ spät entstanden. In den germanischen Sprachen handelt es sich bei dtsch. ja, schwed. ja und engl. yes ursprünglich vielleicht um eine Interjektion (DuDEs) oder um einen Ausdruck mit der Bedeutung 'ja, es sei' (Holthauses). Im Lateinischen gab es noch keine Entsprechung für ja oder oui. Bejahend sagte man einfach: ita est 'so ist es', certe 'sicher', vero 'wirklich, allerdings'. Die bejahende Partikel im Französischen, oui (altfrz. oil) hat sich aus dem lateinischen Wort hoc 'dieser' entwickelt. 'Zur Verstärkung wurde noch das Personalpronomen angefügt: 'dieser ich, dieser' du, dieser er' usw. Das $i l$ (< lat. ille) der 3. Pers. hat sich dann allgemein durchgesetzt: 'dieser er'. In den südfranzösischen Dialekten heisst es auch heute noch nur oc (< lat. hoc 'dieser'). Aus diesem mundartlichen Wort hat sich auch der Name einer französischen Provinz entwickelt: Languedoc (<langue d'oc) 'ocsprache'. Die bejahende Partikel si im Italienischen und Spanischen hat sich aus dem lateinischen Wort sic 'so' entwickelt. Der Ursprung des russischen $d a$ ist nicht genau geklärt. Es dürfte auf den ieur. Pronominalstamm do-zurückgehen, dessen Bedeutung 'er, ihn' war, oder auf ein Verbum do, so dass die ursprüngliche Bedeutung 'geben' wäre (VASMEr).

Natürlich verhält sich die Angelegenheit in den indoeuropäischen Sprachen nicht ganz so einfach, doch sind in den finnisch-ugrischen Sprachen im Prinzip andere Nittel zum Ausdruck der Bejahung verwendet worden, obgleich wir heute in einigen finnisch-ugrischen sprachen bejahende Partikel haben (z.B. fi. kyllä, niin und aus dem Schwedischen entlehnt joo, juu sowie im Ungarischen igen).

Über die bejahende Antwort im Finnischen und Karelischen hat E. A. Tunkelo geschrieben (Vir. 1945: 611-619 und 1948: 
92-94). Er gruppiert sein Material auf folgende Weise: I. die Antwort lautet juu: Tuleeko jääkäri vahtiin? - Juu (Kommt der Jäger auf die Wacht? - Ja); II. joo: Vai jo heität sinäkin renginviran ja rupeat hauppiaaksi... Joo (Gibst du auch schon das Knechtsamt auf und wirst Kaufmamn... Ja). III. kyllä: Tahdotteko juoda lasin olutta? - Kyllä, kiitos (Wollen sie ein Glas Bier trinken? - Ja, danke). Nur als verstärkendes Wort: Kuulitko, mitï se sanoi? - Kyllä, minä kuulin (Hast du gehört, was der gesagt hat? - Ja, ich habe es gehört). - In Feststellungen, Behauptungen, Versicherungen ist das Wort kiyllä allgemein: Kyllä siüäkin oli miestä (ja das war ein Jann); Ymmärän, kyllä hycin ymmärän (Ich verstehe, ja, ich verstehe es gut). Eine Art der Verwendung von kyllä lieurt noch darin, dass der Hörende durch die blosse Nennung dieses Wortes mitteilt, er sei bereit zu tun, worum ihn der andere gebeten oder wozu er ihn aufgefordert hat. Z.B. "... ota sinä hänet hoitoosi ja katso, ettei mitään pahaa hänelle tapahdu." "Kyllä, kyllä", vakuutteli Louise juhlallisen näköisenä. ("Ximm du ihn in deine Obhnt und achte darauf, dass ihm nichts Böses geschieht.» - "Ja doch, ja", versicherte Louise mit feierlicher Miene.)

Tunkelo bemerkt dazu noch: "Meines Erachtens ist dieses versprechende kyllä eigentlich die einzige echte Art, diese 'Partikel' wie einen Satz zu verwenden. Als bejahende Antwort auf eine Frage ist kyllä eine Lehnübersetzung") (S. 615). Dieser Auffassung schliesse ich mich an.

IV. niin: Te asutte setänne luona? - Niin (Ihr wohnt bei eurem Onkel? - Jawohl.) Der Verfasser merkt an: "Das auch allein als Antwort dienende niin ist eigentlich und ursprünglich ein demonstratives Adverb, das u.a. in Fällen auftritt wie "Nyt onkin ihmeellisen kaunis aamu" - "Niin on" ("Heute ist doch ein wunderbar schüner Morgen» - "So ist es») (S. 616). V. Das betonteste bzw. wichtigste Glied der Frage - ein Wort oder eine Wortgruppe - wird wiederholt: Kotoapäinkö se Matti ajelee? - Kotoapäinpä sitä ... (Kommt der Matti ron zu Hause gefahren? - Ja, von zu Hause...) Kuulitko mitä kysyin? - Kuulin (Hast du gehört, was ich gefragt habe? Ich habe es gehört); Jalanko sinä kuljit koko taipaleen? - Jalan 
(Bist du die ganze Strecke zu Fuss gegangen? - Zu Fuss). Die Personalpronomina wechseln natürlich und auch die Demonstrativpronomina können sich ändern: Minäkö kuorsaan? - Sinä (Ich schnarche? - Du); Tässäkö sinä silloin seisoit? Siinä seisoin. (Hier hast du damals gestanden? - Da habe ich gestanden). "Als bejahende Antwort wird die finite Verbform wiederholt, die das erste Wort der Frage bildet und an die die Fragepartikel -ko, -kö angehängt ist, wenn das Wort auch nicht das betonteste Glied der Frage ist: Ovatko lehdet kuolleet? Ovat (Sind die Blätter abgestorben? - Sie sind es.)" (S. 618). VI. Eine bejahende Antwort, die durch Umschreibung ohne Wiederholung eines oder mehrerer Worte des Fragenden gegeben wird: Jalanko sitä on kulettu? - Eipähän sitä köyhällä hevostakaan lie ... (Zu Fuss kommt man daher? -- Ein Armer dürfte wohl kein Pferd haben ...)

In seiner Untersuchung über die bejahende Antwort im Karelischen kommt Tunkelo zu dem Ergebnis: "Die Karelier des ehem. Gouvernements Twer wie auch anderwärts verwenden wohl die russische Partikel $d a$ als kopulative Konjunktion, z.B. naine da mužikka 'Frau und Mann'. Als bejahende Antwort tritt sie wenigstens nicht auf . .., obgleich sie im Russischen auch dic Bedeutung 'ja, jawohl' hat..., positiv wird nur auf eine Art geantwortet, indem nämlich das am stärksten betonte Glied der Frage wiederholt wird, wobei jedoch im Bedarfsfall die Person des Verbums oder ein anderer Ausdrucksträger des Subjekts wechselt bzw. das Substantiv oder der sonstige "Nimo" durch ein Pronomen ersetzt wird" (Vir. 1948, S. 93).

Auch im Ungarischen wird eine bejahende Partikel verwendet, das Wörtchen igen, jedoch nicht sehr häufig. Gewöhnlich wird das wichtigste Wort oder die Wortgruppe wiederholt. Handelt es sich um einen Verbalsatz, wird das Verbum wiederholt: Ég a tüz a kályhában? - Ég (Brennt das Feuer im Ofen? - Es brennt). Hat das Verb jedoch ein Präfix, wird nur das Verbalpräfix noch einmal gesagt, ein Zug, der charakteristisch ist für das Ungarische. Ungarisch ist vielleicht die einzige Sprache in der Welt, wo eine derartige Antwort die Regel ist. In Österreich verspottet man die Ungarn deshalb, dass sie auf 
die Frage: verstanden? in ungarischer Art mit ver antworten. Es heisst ja im Ungarischen tatsächlich: Megértetled? - Meg (Hast du verstanden? - Ja). Für die Ausländer, auch für die Finnen, ist eine solche Art der Antwort ebenso fremd wie eine aus Savo. Wenn einer fragt: likö out salamelta kotosin? (Bist du in Iisalmi zu Hause?), kann ein anderer antworten: Enkä, vuan $K \ddot{a} k$ (Nein, sondern in Käk). ${ }^{1}$

Bezeichnend für das Ungarische ist es ferner, dass es zwei Verbpaare kennt, deren einer Teil, jeweils die Annäherung an den Standort des Sprechenden oder aber die Entfernung von ihm ausdrückt. Es sind die Paare jönni--menni für 'kommen' und hozni - vinni für 'bringen'. Auf die Frage Eljössz-e hozzám (Kommst du zu mir)? wird bejahend geantwortet: Megyek oder elmegyek (Ich komme, eigtl. ich gehe). Oder verneinend: Nem megyek (Ich komme nicht, eigtl. ich gehe nicht). Wenn gefragt wird: Hozol bort (Bringst du Wein)? lautet die Antwort Viszek (Ich bringe, eigtl. ich führe). Aufschlussreich ist, dass die gleiche Ausdrucksweise auch im Wogulischen gebräuchlich ist. Wir können also mit voller Berechtigung vermuten, dass diese Perspektive der Antwort im Ungarischen uralt ist und auf der ugrischen Ursprache beruht.

Das Material der obugrischen Sprachen, das dieser meiner Untersuchung zugrundeliegt, stammt aus den folgenden Textsammlungen: wog. A. AHLQvist, Wogulische Sprachtexte nebst Entwurf einer wogulischen Grammatik (MSFOu VII); MusKácsi B., Vogul Népköltési Gyűjtemény I-IV (= VNGy); A. Kannisto-M. Limola, Wogulische Volksdichtung I-VI (MSFOu 101, 109, 111, 114, 116, $134=$ WVd); P. N. ZuL'ov, Iovintan magys kniga, 1933; Cernezov-Černezova, Man mojtanuv und Mansi mojt 1935; B. Kícuíx, Chrestomathia Vogulica, 1963 (= ChrV); II. Носов, Витя Малеев школат ос юн, .Јенинград, 1955 (l̈bersetzung); ostj. A. AHLQvist, Über die Sprache der Nordostjaken, Helsingfors 1880; S. PATKaxov, Die Irtysch-Ostjaken und ihre Volkspoesie, St. Petersburg 1897 (= IO); PÁPAY J., Osztják Népköltési Gyüjtemény, Budapest 1905 (= ONGy); PÁPAY J., Északi osztják nyelv-

1 Iisalmi und Käkisalmi sind Ortschaften. 
tanulmányok, Budapest 1910 (= ÉONyt); REGULY-PÁPAYZsiraI, Osztják hősénenek I-III $(=\mathrm{OH})$; W. STEInitz, Ostjakische Volksdichtung und Erzählungen I-II, TartuStockholm 1939, 1941 (= OVE). Die obugrische Übersetzungsliteratur habe ich (ausser dem erwähnten Buch von Nosov) nicht benutzt. Beim Zitieren der Beispiele habe ich die Transkription von Munkácsi und Cernezov ein wenig modernisiert.

Es gribt sehr wenig Fragen in der Lyrik, in den Schicksalsliedern, den Bärenliedern, den Gebeten, den Heldenliedern, mit anderen Worten in den monologförmigen Dichtungsarten. In den langen ostjakischen Heldenliedern, die oft über 1000 Verse umfassen, werden gewöhnlich nur rhetorische Fragen gestellt, auf die nicht geantwortet wird. Die Helden unterhalten sich nicht, sie halten sich gegenseitig lange und feierliche Ansprachen und wenn einmal auf eine Frage geantwortet wird, so geschieht es gewöhnlich verneinend, wie es sich für kämpfende Helden geziemt. In den Erzählungen und Sagen treten häufiger Fragen und Antworten auf. Doch habe ich bei der Lektüre beinahe der ganzen ursprünglichen obugrischen Volksdichtung, die bisher veröffentlicht ist und viele tausend Seiten umfasst, nicht mehr als 211 wogulische und 58 ostjakische bejahende Antworten gefunden, insgesamt also 269 Stück. Auf dieser Grundlage kann man jedoch bereits einen Überblick geben über die obugrische Art des Antwortens.

Nach der Art der Antwort teile ich mein Material in sechs Gruppen ein:

1. In der Antwort steht eine bejahende oder verneinende Partikel. $(+p,-p) \mathrm{R}$

2. In der Antwort wird die Frage wiederholt. $\mathrm{R}=\mathrm{Q}$

3. Die Frage wird durch Wiederholung des betontesten Gliedes beantwortet. $\mathrm{R}=\mathrm{q}$

4. Eine verneinende Gegenfrage wird gestellt. $R=-Q$

5. Die Frage wird ohne Wiederholung eines ihrer Glieder beantwortet. $\mathrm{R}=\mathrm{x}$

6. Die Antwort ist bedingend, einschränkend oder ausweichend. 
Als Untergruppe erwïhne ich jeweils die Art der Frage oder Aufforderung, Mitteilung:

a. Positive Frage $(+Q)$

b. Negative Frage $(-Q)$

c. Doppelfrage (positive und negative) $( \pm Q$ )

d. Aufforderung ( + Adh.) [adhortatio]

e. Aufforderung mit Auswahlmöglichkeit ( \pm Adh.)

f. Mitteilung, Verkündung (I) [indicatio]

In den Unteroruppen erfolgt die Reihenfolge nach den Sprachen und Dialekten. Leider liegt nicht bei allen Dialekten eine gleichmässige Vertretung vor: WogX 93, W 10, 088 , S 20; OstjN (Ahlquist, Pápay, Steinitz) 41, S (Patkanov) 17 Beispiele.

1. Da ich in den ursprünglichen obugrischen Texten keinen Beleg dafür gefunden hatte, dass die Antwort durch die blosse bejahende Partikel ausgedrückt wird, untersuchte ich einen aus dem Russischen übersetzten wogulischen Roman (N. Nosov, Витя Малеев школат ос юн. Ins Wogulische übersetzt von E. I. Rombaxdejeva, Leningrad 1955). Der wogulische Teil des Buches umfasst 221 Seiten und der russische Urtext ist ebenfalls abgedruckt. Ich suchte nach den Antworten, die in russischen Text lediglich die bejahende Partikel $\partial a$ zeigen. Im ganzen Roman kommen nur 5 solcher Fälle vor. In zwei Fällen verwendet die Übersetzerin die bejahende Partikel ocmblebl. , die in ursprünglichen Texten überhaupt nicht vorkommt. Es handelt sich nicht um ein Lehnwort sondern um eine Zusammensetzung aus $\bar{o} s$ 'und' und tigl 'danach, damn'. (Munkácsi kennt zwar ōs-ti 'natürlich', doch nie alleinstehend.) Значит, Костя просил тебя обманить меня? - Да (S. 330). I) wogulische I'bersetzung lautet: Kocm.q нангын ану.n .lanлангкв лавыс? - Oстыгы. (S. 164, Hat Kostja dich gebeten, mich zu betrügen? - Natürlich). | Значит ты нарочно пропустил, когда писа.пі днктант, а потом не проходил, потому что у тебя не было записки от матери! - Да. (S. 331). Wogulisch: Нанг диктант хасмув порат намыл урок ху.льсын тувыл аманыл хансим нәпак-ломт ат осьмын магыс, урокытн ат ёхталалсын? - Ocmbızb.л. (S. 165, Bist du absichtlich 
während des Diktierens weggegangen und dann nicht zurückgekommen, weil du die Aufgabe über die Mutter nicht hattest? - Natürlich.)

In drei Sätzen ändert die Übersetzerin jedoch die Art der Antwort: Ты новнчок, Костя? - Да (S. 250). Wogulisch: Нанг, Кост.я, йиıьпnи пыгрись? - П̆иıьпи пыгрись. (S. 44, Bist du ein Anfänger, Kostja? - Ein Anfänger); II даже ноги? - Да (S. 326). - †'bersetzung:.Таг.лагын ос аг.иынганвег - $a$ ? - Oc. (S. 158; Tun auch deine Beine weh? - Auch die); Ты Малеев, ведь друг ІІишкина? - Да (S. 335). Нанг май Малеев, III ишкин юрт-а? - ШІиикин юрт. (S. 172, Dı, Malejev, bist der Freund von Šiškin, nicht wahr? - Der Freund von Šiškin). Die bejahende Antwort wird auch anders vervollständigt: Здесь веґь четвертий класс? - Здесь (S. 233).

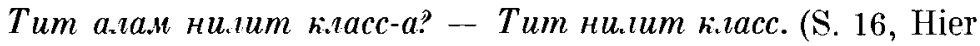
ist ja sicher die vierte Klasse? - Hier. In der C̈bersetzung: Hier ist die vierte Klasse.)

In sechs Fragen, wo auch die Antwort in der russischen Sprache länger ist, jedoch mit dem Wort $\partial a$ beginnt, schreibt die Übersetzerin viermal ocmbmbı (natürlich), zweimal coль (wahrlich) und setzt die Antwort nach dem russischen Lrtext fort (SS. 67, 266; 72, 269; 102, 289; 134, 309; 150, 320; 194, 351).

Auch hieraus geht hervor, dass eine Antwort vom Typ des blossen ja, jarohl dem Wogulischen fremd ist; von den mir bekannten 269 obugrischen Antworten sind nur zwei so geartet, dass die blosso bejahende Partikel als Antwort dient; auch sie sind İbersetzungen aus dem Russischen.

Es ist bezeichnend, dass im Russisch-wogulischen Wörterbuch von Rombandejeva die wogulische Entsprechung des russischen Wortes $\partial a$ fehlt. Die Verfasserin veranschaulicht die positive Antwort durch ein Beispiel: russ. Пойдёшь с нами? Да. Wog. Ман ётув минәгын? Минэгум. (Gehst du mit uns: - russ. Antwort: Ja, wog. Ich gehe.)

Antworten, in denen eine bejahende Partikel auftritt, gibt es insgesamt 28.

a. Positive Frage: wog. (Man mojtanuv S. 6) So Teqam, tuijig jemti, man sort arpi varilamen-a? - Ja, . . mak varilamen! Mań sort arpi mak varilamen. Mein Freund, (wenn) der 
Sommer kommt, machen wir einen kleinen Fischzaun um Hechte zu fangen? - Gewiss, ... wir machen es sicherlich! Wir machen einen kleinen Fischzaun um Hechte zu fangen; (S. 10) Elva-pizriś, putan tinaleln? - Ja, tinalilum. Neffchen der Frau, verkaufst du deinen Kessel? - Ja, ich verkaufe ihn;

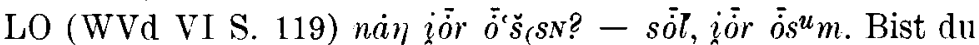
stark? - (Es ist) wahr, ich bin stark / (I S. 36-37) KU

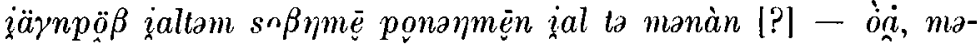

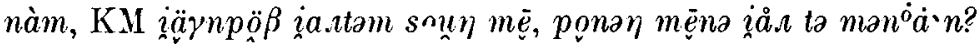
-- $\dot{o} \mathfrak{a}$, mana`m. Gehst du nun hinunter auf die von deinem Bruder erschaffene krustige Erde, haarige Erde? - Jawohl, ich gehe; (III S. 58-59 zweimal, ähnliche noch S. 61-62

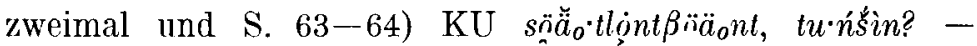

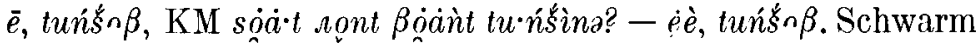
von sieben Gänsen, steht ihr? - Jawohl, wir stehen; (ebenda

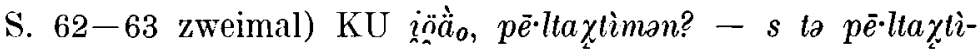

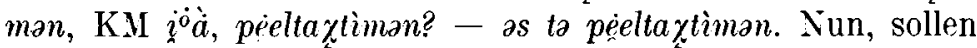
wir tauschen? - Nun, tauschen wir also; (S. 92-93) KU

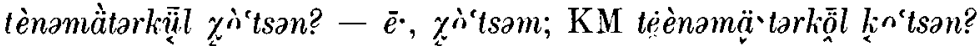
- $\dot{e} \cdot e$, lintsam. Hast du ein Bröckchen Speise gefunden? Gewiss, ich habe gefunden; (S. 96-97) KU sə·mtä̈äot $\beta \beta$ t"ïäot!

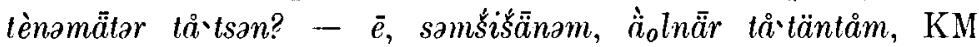

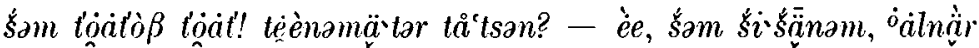
tåtanta'm. Lieber Vater, Vater! Hast du Speise gebracht? Gewiss, meine lieben Kinder, etwas bringe ich \| ostj. (AHLqv. 4) N xodaś ant ulmisan? - jena ulmisem. Was hast du nicht geträumt (hast du etwas geträumt)? - Wahrhaftig, ich habc

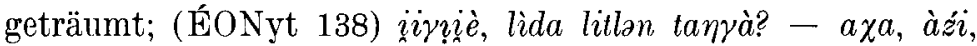
lida lillam. Mein Söhnchen, möchtest dı vielleicht essen? Ja, Väterchen, ich möchte essen; (S. 152) zodị, naunèmlàn

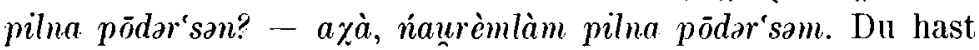
mit deinen Kindern gesprochen, nicht wahr? - Ja, ich habe mit meinen Kindern gesprochen.

b. Negative Frage: wog. (VNGy I S. 16-17) N kit èlmip kasäjil at majwäsan? - sōl! . . kit èlmip kasäjil majwäsom. Gab er dir kein zweischneidiges Messer? - Wahrlich, er gab mir ein zweischneidiges Messer | (WVd III S. 58-59 zweimal)

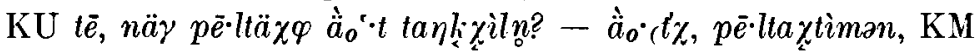




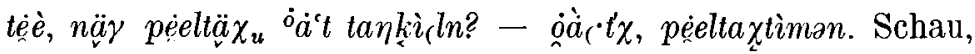
willst du nicht tauschen? - Jawohl (?), tauschen wir | (VNGy

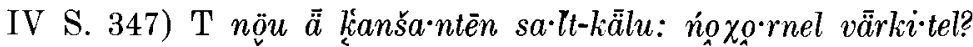
- $\bar{e}, k$ kanša ntēm. Weisst du nicht, woraus ein Bastseil gemacht wird? - Doch, ich weiss es $\|$ ostj. (OH III S. 154-55) N lahring go telen pa koltä enhten mui adom [?] -- jäne lahring ho tarom telen engi lite măsl... Wäre es vielleicht schlecht, dein Kleid des mit einem Panzerhemd versehenen Mannes abzulegen (eigtl. das Ablegen, dein Ablegen)? - Wahrlich, das starke Panzerhemd des mit einem Panzerhemd versehenen Mannes muss ich ablegen |(IO II 148-49 zweimal) S nur-pa virin tagirna vir-sêmita tê-not, mole notat ei-tu-ba têvîden? ćoida têvîdem. Hast du nicht in der That an dem mit Blut befleckten Orte mit diesem (deinen) Schnabel Bluttröpfchen genossen? - Wahrlich, ich habe (sie) gegessen.

c. Doppelfrage: (VNGy I S. 23) N a-man mis-lū sūsäs èri,

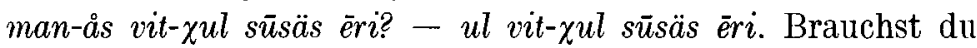
Tiermitgift oder Fischmitgift? - Ich brauche natürlich Fischmitgift.

f. Mitteilung: wog. N (ZuL'ov, Lovintan magys kniga S. 51)

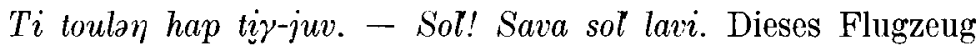
kommt hierher. - Wahrlich, Sawa hat wahr gesprochen !

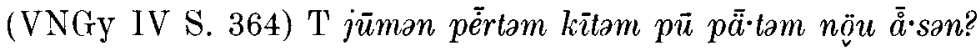
- kèrrt, äm $\bar{a} \cdot s a m$. Sicherlich bist du der unserem Vater verkaufte Verbannter-Sohn. - Wahrlich, ich bin es.

Die bejahenden Partikeln lauten folgendermassen: im Nordwogulischen $s \bar{l} l$ 'wahrlich', $j \bar{a}$ 'na', $u l$ 'übrigens', an der Konda und Tavda sind es die Interjektionen $\dot{o} \dot{a}, \bar{e}, s t a$, ät' $\chi$, deren Bedeutung recht unklar ist und die ungefähr mit 'sieh, he, aha' zu übersetzen sind, an der Tavda auch kẻrt 'wirklich'. Im Nordostjakischen haben wir jena, aұa, im Süden ćoida.

In den erwähnten Beispielen gehören Interjektion und Partikel nicht organisch zur Antwort selbst, sie sind auch an sich keine Bejahung, sondern sie verlangen eine Vervollständigung. Eine Partikel oder Interjektion kann die positive Antwort nicht ersetzen, sie intensiviert sie nur, spielt eine Nebenrolle darin und kann ohne Nachteil wegbleiben.

Das Unwesentliche und Unorganische einer Partikel oder 
Interjektion kommt auch in folgendem Umstand zum Ausdruck. Ein merkwürdiger Antworttyp lässt in den obugrischen Sprachen eine bejahende Antwort mit einer verneinenden Partikel beginnen (in einem Fall enden). Von neun derartigen Antworten erfolgen vier auf eine Frage oder Mitteilung, worin zwei Möglichkeiten genannt sind.

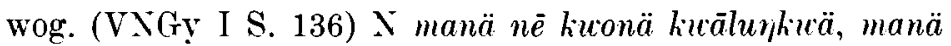

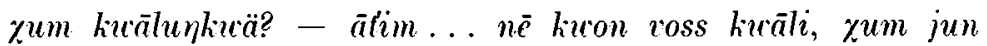
voss ā li. Soll die Frau hinausgehen oder soll der Mann hinausgehen? - Nein, die Frau soll hinausgehen, der Mann soll zu Hause bleiben. ! (KáLMÁx Manuskr.) Ob minanke man ät? $\bar{a} f i$, minèrm. [Soll ich] gehen oder [soll ich] nicht gehen? Nein, ich gehe. | (WVd II, S. 650) K äsantaðta'nka, ma`nan

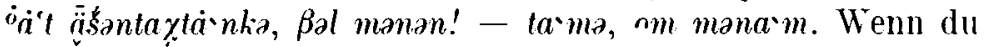
dir vertraust, (so) geh, wenn du dir nicht vertraust, (so) geh nicht! - Nein, ich gehe.

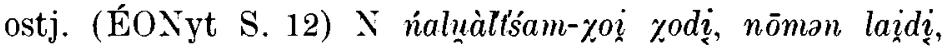
pàm ăr, mola iln zoịddì pàm ār? - andàm! iln zoịdị pàm ār. Pfeil-Spanmann, gibt es mehr aufrecht stehendes Gras oder gibt es mehr liegendes Gras? - Nein, liegendes Gras gibt es mehr.

In diesen Antworten ist die verneinende Partikel psycholorrisch gut verständlich. Der Antwortende verneint mittels der negativen Partikel die eine Möglichkeit und bejaht im folgenden 'Teil der Antwort die andere.

Eine solche Antwort kamn jedoch auch dann verwendet werden, wenn die Frage keine zweite Möglichkeit bietet: wog.

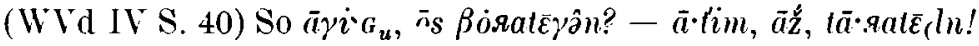
Mägdlein, strebst du noch (danach)? - Nein, Vater, lass mich

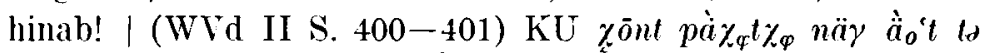

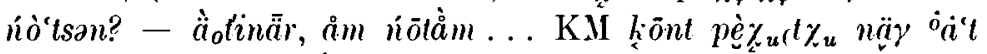
ta nótsan? - óátinär, nm nótå:m. Würdest du nicht helfen, die Kriegerschar totzuschiessen? - Nichts, ich helfe. (S. 498

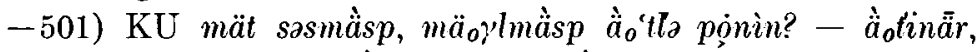

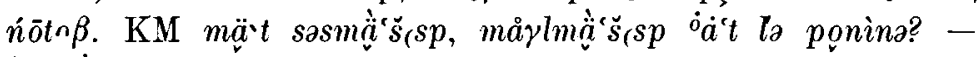

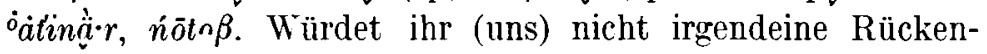
stütze, Bruststütze geben? - Ach, nichts, wir helfen (euch). I

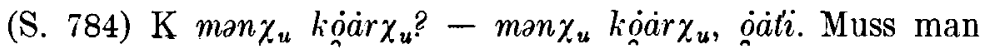


gehen? - Man muss gehen, [nein.] | (Man mojtanuv S. 8) .Ja, teham, vos tinaleln! - Atin, tinalilum-ke, tinalilum. Nun, mein Freund, verkaufe es (mir)! - Nein, wenn ich es verkaufe, verkaufe ich es.

Die verneinende Partikel in den obenstehenden Antworten weist auf einen anderen Nebengedanken hin. Bei der ersten bedeutet die verneinende Partikel, dass die Bärin, die Tochter von Numi-Toorum, gegen den Willen des Vaters zur Erde will. Im zweiten und dritten Satz wird um Hilfe gegen den angreifenden Feind gebeten. Die verneinende Partikel kann z.B. bedeuten: traure nicht, es ist nicht schlimm, wir werden schon helfen. Das in der vorletzten Antwort am Schluss stehende óati drückt vielleicht etwas derartiges aus: Wir müssen gehen. Es hat keinen Zweck mehr, hier zu sein.

In der Erläuterung der Texte wird nirgonds, weder bei Munkácsi noch bei Kannisto, erwähnt, dass es sich hier vielleicht um einen Einfluss des russ. ничего handeln kann, das ja in der Umgangssprache als Antwort häufig verwendet wird. Hичего 'es macht nichts' würde aber nur für die drei Beispiele ron der Konda gut passen.

2. Die zweite Gruppe bilden jene Fälle, wo die Frage in der Antwort wiederholt wird $(R=Q)$. Hier ändert sich natürlich die Person: wenn Subjekt und Prädikat der Frage in der zweiten Person stehen, tritt in der Antwort die erste Person auf und umgekehrt. Handelt es sich um die dritte Person, kann die Frage in der Antwort unverändert wiederholt werden. Das Schema ist also:
a. $\left(\mathrm{S}_{1} \mathrm{P}_{1}\right)$ ? $-\mathrm{S}_{2} \mathrm{P}_{2}$
b. $\left(S_{2} P_{2}\right) ?-S_{1} P_{1}$
c. $\left(\mathrm{S}_{3} \mathrm{P}_{3}\right)^{?}-\mathrm{S}_{3} \mathrm{P}_{3}$

Das betrifft natürlich nur den Singular.

Obgleich diese Gruppe die grösste ist, -68 Beispiele bzw. $25 \%$ des ganzen Materials gehören dazu - hat doch in keinem Fall die Frage eine negative Form.

Beispiele:

a. wog. (Man mojtanuv S. 6) So Ekva piyriś, jun olezin? Am jun olerum. Neffchen der Alten, bist du zu Hause? Ich bin zu Hause; (ebenda \$. 25) Aman sol aś ośsum? - Sol aś ośsm. Aśin ti As-otern alces. Hatte ich wirklich einen Vater? 
- Du hattest wirklich einen Vater. Dein Vater wurde vom ObFürsten getötet; (Vitja Malejev S. 172) Нанг май, Малеев, Шиикин юрт-а? - Шиикин юрт. Bist du, Malejev, Schischkins Freund? - (Ja,) Schischkins Freund; (ebenda S. 16) Tит алам нилит кгасс- - - Tит нилит класс. Ist hier die vierte Klasse? - (Ja,) hier (ist) die vierte Klasse; (WVd VI S.

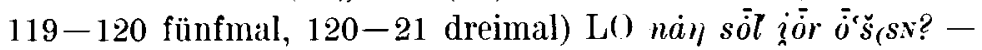

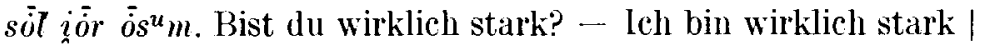
(ebenda II S. 230-31) KU $n \ddot{a} \cdot \gamma m \overline{\dot{a}} \cdot n ?-a m m \bar{a} m$, KM $n \ddot{a} \cdot \gamma$ $m \bar{e} \cdot n ?$ - n'm mền. Deine Erde? - Meine Erde; (S. 30) KM

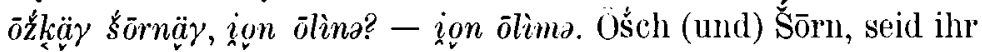
zu Hause? - Wir sind zu Hause; (S. 240-41) KU œulp $\eta \chi$

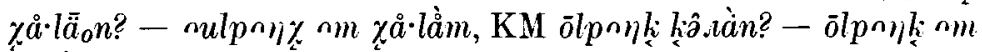
liâ.ıàm. Suchst du (mein) Verderben? - Ich suche (dein) Ver-

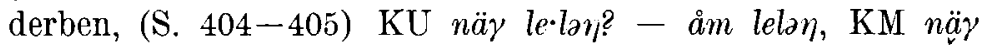
lalanna? - om lalanna. Bist du am Leben? - Ich bin am

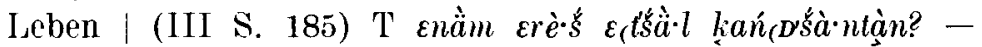

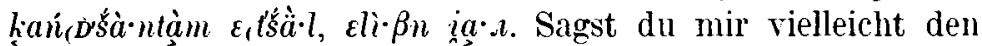
Tod vorher: (Weisst du mir vielleicht den Tod?) - Ich sage

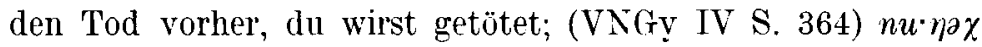
$\ddot{j} \cdot s a n$ ? - $\ddot{a} \cdot m a \chi ~ j i \cdot s a m$. Bist du allein gekommen? - Ich bin allein gekommen $\|$ ostj. (AHLQv. 4) $\mathrm{N}$ jena pēla vantsen? jena vantsem. Sahst du ihn wirklich? - Ich sah ihn wahrhaftig;

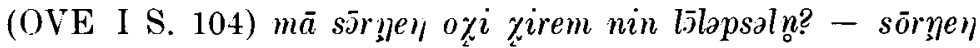

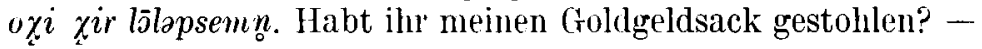
Wir stahlen den Geldsack.

c. wog. (VNGy IV S. 172) N masxatim? aiti? - masxatim $\bar{a} l i$. Ist er angezogen? Nicht? - Er ist angezogen $\mid$ (S. 380) K khot jit-joxtilam, äm närilam? - khot jo\%tilan ... Hole ich ihn ein, oder bemühe ich mich umsonst um ihn? - Du wirst ihn irgendwo einholen; (WVd II S. 232-33) KU ä $\ddot{a}_{o} \grave{a}_{o} n p o \ddot{n} \beta \ddot{a}_{o} n$

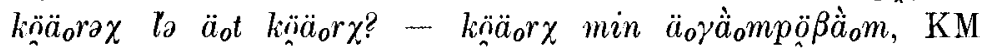

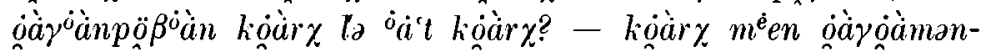
pößöàman. Sind deine Jungen (dir) nötig, oder sind sie (dir) nicht nötig? - Unsere Jungen sind (uns) nötig; (S. 652) KM

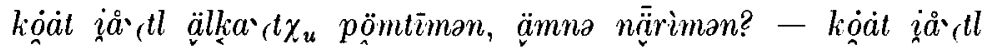
pömtiman. Beginnen wir mit (blosser) Hand zu kämpfen oder was tun wir? - Beginnen wir mit (blosser) Hand ... I (III 


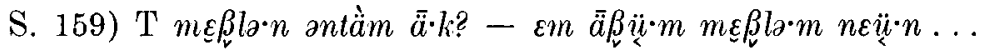
Gibst du sie, oder nicht? - Ich gebe dir meine Tochter; (S. 167,

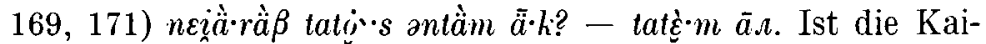
serstochter gebracht oder nicht? - Sie ist gebracht \| ostj. (OVE I S. 159) N qoti jêttšasan muj antum? - mä in jëttšasam. - Bist du etwa fertig oder nicht? - Ich bin nun fertig; (ÉONyt

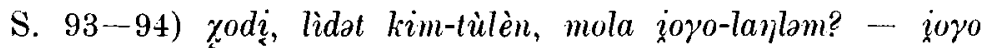
lanà! - Wie, holst du das Essen heraus oder soll ich hineingehn! - Komm herein! | (IO II S. 2-3) S An sevrantteu, ada at jêvedîtteu? - at jêvedîtteu! Schlagen wir uns (mit den Schwertern) oder schiessen wir (Pfeile ab)? - Lasset uns schiessen! (S. 106-107) tam voćetna ûrt ûtt-ta, metta xon ûtt? - xon ûtt. Lebt in dieser Stadt ein Held oder ein König? -- Ein König lebt (hier); (S. 124-25 dreimal und 126-27) at sevranttemen-na, metta at poxtanttemen? - at sevranttemen! Werden wir uns schlagen oder uns stossen? - Schlagen wir uns!

d. wog. So (Man mojtanuv S. 11) Ja, tinaleln api $\gamma !$ - Ja, kit luv mayas tinalilum. Nun, Neffe, verkaufe es! - Nun, ich verkaufe es für zwei Pferde; (ebenda S. 15) Nan os toteln! Am totilum. Bring es auch mit! - Ich bringe es mit / (WVd III

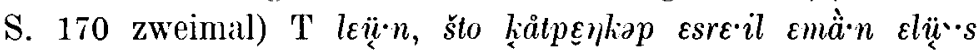

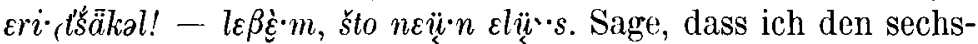
köpfigen Teufel mit der Stange erschlagen habe! - Ich sage, dass du ihn erschlagen hast $\|$ ostj. (ÉONyt S. 24) $N$ imi

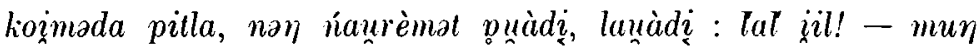
svyà pulu. Wenn die Frau zu zaubern anfängt, heulet ihr Kinder, saget: der Feind kommt! --.- Wir werden schon heulen.

Es ist mitunter schwer, diese Gruppe von der folgenden zu trennen, denn die Antwort auf eine kurze Frage kann auch bei der Wiederholung der Frage nur ein Wort umfassen:

a. wog. (VNGy II S. 115 zweimal) N apikwa joxtasan? -

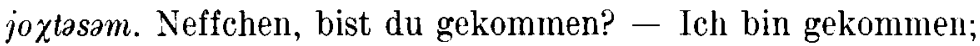
(IV S. 172) jātä, åjilmatwas? - åjwəs. Hörst du, ist er eingeschlafen? - Er ist eingeschlafen; (WVd I S. 133, 134, 135,

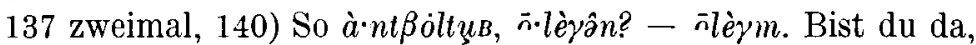
Hornschaber? - (Ja,) ich bin da; (S. 137 zweimal, 139, 140, 141) $\dot{a} \cdot{ }^{n} t \beta \dot{t t p}{ }^{2} n s a_{{ }_{G} \beta a t a \beta e s ?}-s a_{(G} \beta a t a \beta e s$. Ist dein Hornschaber zerbrochen? - (Ja,) er ist zerbrochen; (S. 138) ànt- 


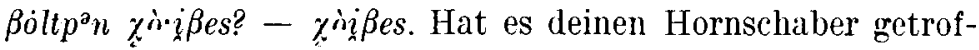
fen? - (Ja,) es hat ihn getroffen; (S. 138, 139 zweimal) $\bar{r} l \grave{y} \gamma n$,

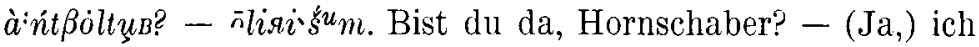

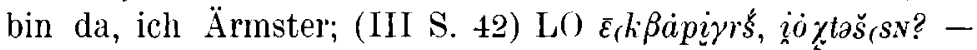
ijozto $s^{u} m$. Neffchen der Alten, bist du gekommen? - (Ja,) ich bin gekommen; (Kálumíx Manuskr.) Ob pigkem, nar? - am. Söhnchen, bist du (es)? - Ich bin (es) | (WVd I S. 182-83)

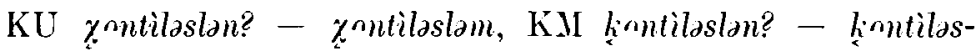
lam. Hast du ihn gefunden? - Ich habe ihn gefunden; (II S. 384-85) KU äpi, ùrilno - ürilam, KM äpi, ūrìln? ürilam. Junge, wartest du auf ihn? - Ich warte auf ihn;

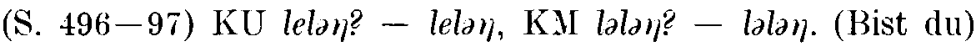
lebendig? - (Ja, ich bin) lebendig; (V S. 123) KM naßäip?

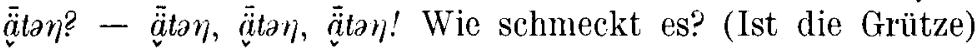
süss? - (Ja, sie ist) süss, süss, süss!

d. wog. So (Mańsi mojt S. 5) Lreln! - Lrilum. Wache! Ich wache I (VNGy IV S. 349) T nöu . . jun åmå.tton, ļóro.m

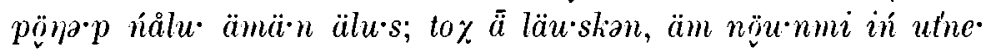

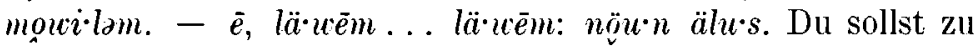
Hause erzählen, dass ich die dreiköpfige Schlange getötet habe; wenn du es nicht so sagen werdest, werde ich dich jetzt im Wasser ertränken. - Ja, ich werde es sagen, so werde ich sagen, dass du sie getötet hast.

Meiner Auffassung nach ist die Wiederholung der Frage die primitivste und ursprünglichste Art des Antwortens. Die anderen Formen haben sich daraus entwickelt.

3. Eine sehr übliche und für die finnisch-ugrischen Sprachen typische Art des Antwortens ist die Wiederholung des am stärksten betonten Wortes der Frage, gewöhnlich des Verbums. Das Verb wird wiederholt:

a. wog. (VNGy I S. 26) N jåməsä̈kw jälsən? - jälsam. Bist du wohl gefahren? - Ich bin (wohl) gefahren; (II S. 9) nauramat! pusan-ta $a^{\gamma}$ il jälsän? - jälsū. Kinder, seid ihr gut gefahren? - Wir sind (so) gefahren; (IV S. 172) jüntop ảnśi? - āńśi. Hat er ein Panzerhemd? - Er hat (es); (WVd III S. 20) LO

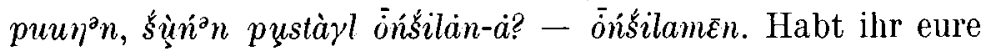
Rentierherde (und) eure Habe in Verwahrung? - (Ja,) wir haben; (S. 45) lī $\beta r$ ónś̀̀yn? - jónśèym. Hast du cin Ge- 
fäss? - (Ja,) ich habe (eins); (Man mojtanuv S. 29) Maıkcla hontiglaslan? - Hontiglaslum. Hast du die Eule gefunden? -

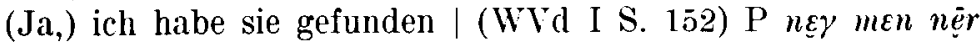

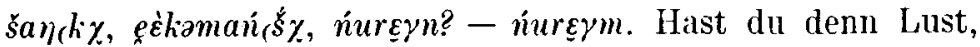
Nüsse zu beissen, mein Onkel? - Ich habe Lust; (S. 153)

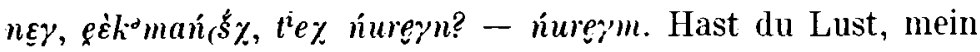
Onkel, zu essen? - Ich habe Lust | (II S. 230-31, 302-303,

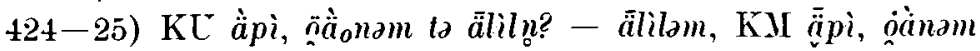
tac $\gamma$-äli,lu? - älilam. Junge, tötest du mich nun? - Ich töte

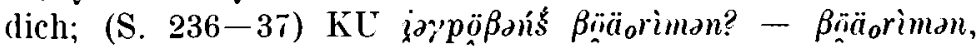

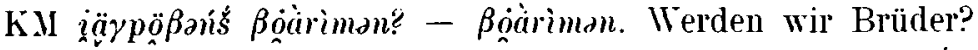

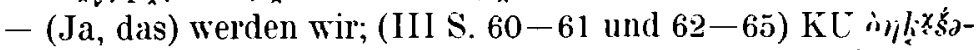

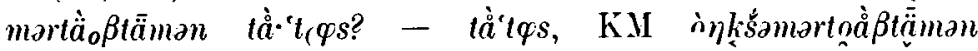

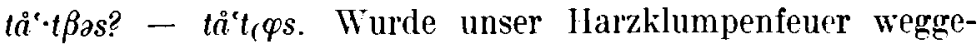
bracht? - Es wurde weggebracht; (S. 100-101) $\mathrm{KC} n \dot{n} \cdot \chi^{2}{ }^{2}$

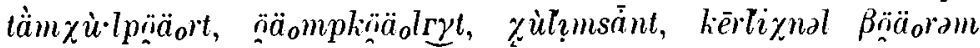

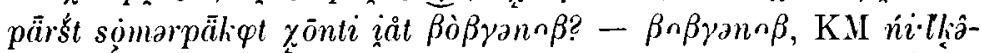

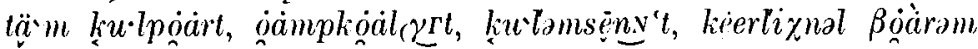

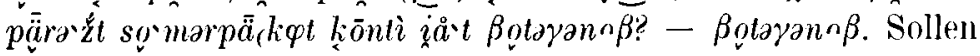
wir das schleimige Fischbrett, die Hundestricke, die (birkenrindenen) Aschenschalen, die aus Eisennägeln gemachten Eisenstangen (und) den Barschrogen als Kriegsheer mitrufen? - Wir rufen sie | (VNGy IV S. 358 zweimal) T táro $\eta-p \bar{u}$,

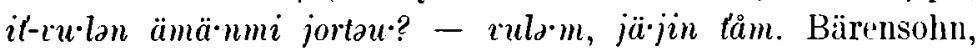
nimmst du mich mit als Gefährten? - Ich nehme dich, komm

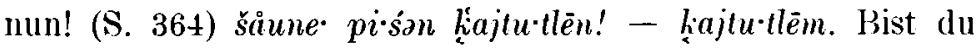
gesund (läufst du gesund herum)? - $\left(\mathrm{J}_{\mathbf{a}},\right)$ ich bin (ich laufe herum) | (Anlqv. MSFOu VII S. 131) Taile ronluxt? - Tai. Ist's bequem zu sitzen? - Ja (es ist bequem) \| ostj. (AHLQv. S. 10) $\mathrm{X}$ nin lilten? - alt lìlmen, sāmlamen vaxlaten. Ihr esset? - Darum essen wir, (weil) unsere Herzen verlangen; (ÉOXyt S. 97) pàm-lagar-tòrbi zoi ollan? - ollam. Bist du der Mann mit der Grasbinsenmütze? - Ich bin es; (S. 102) zodį, zàtna

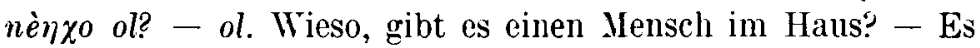

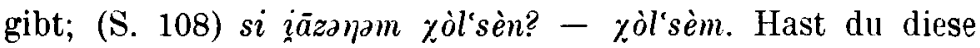
meine Rede gehört? - Ich habe sie grehört; (S. 157) zodi, igan seual seusèn? - seusèm. Wieso, hast du deinem Jann einen Zopf gezöpft? - Ich habe gezöpft | (IO II S. 128-29) S mant 
nêna veden-na? - vedem. Wirst du mich zur Frau nehmen? Ich nehme dich.

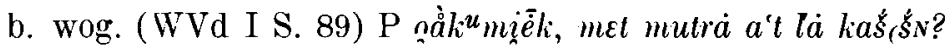
- kaššlm. Meine Tante, weisst du nicht irgendein Zauber-

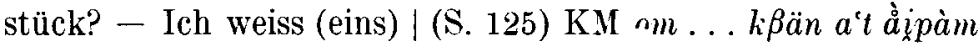
$l i$ ? - nei... à̀ipàn. Werde ich nicht frei? - Du wirst frei werden.

c. wog. (Man mojtanuv S. 9) So Kon-alilamen, man juvśaltsimen? - Juv-śaltsimen. Töten wir ihn draussen, oder gehen wir hinein? - Wir gehen hinein.

d. wog. (Man mojtanuv S. 5) Jomaśakce poseln! - Am

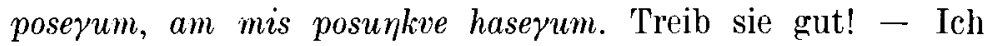
treibe sie, ich verstehe Kühe zu treiben $\mid$ (WVd I S. 128) T $n \dot{0}$

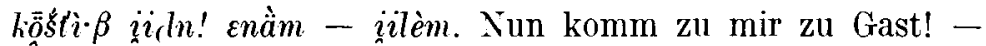

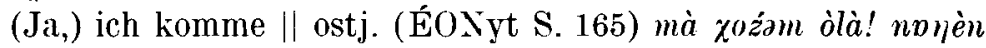
ï $\chi$ ¿̇ugànnị tvịlèm. - malaị ădam. ollam. Bleib bei mir, ich werde dich wie meinen Sohn halten. - Warum (wäre dies) schlecht. Ich bleibe.

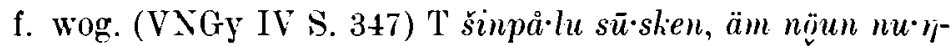

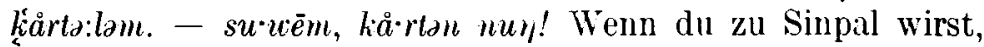
werde ich dich heraufziehen. - Ich werde es, zieh mich hinauf! II ostj. (AhLqv. S. 5) N neri tada ula, ma lorilem. - lonita lonia! Du sollst hier bleiben, ich gehe hinein. - Geh, wenn du gehst! | (IO II S. 104-105) S. man zotat jâxtam, xun unta ei xôt lôtna omistam? - jânxa, xova at menà! Ich werde mal fortgehn, wie lange (bis wann) soll ich (noch) im engen Raume eines Hauses sitzen? - Geh, aber entferne dich nicht zu sehr!

Oft wird das Verb auch zweimal wiederholt:

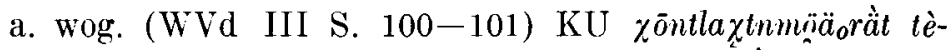

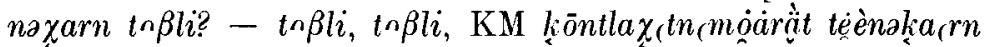

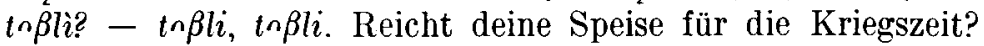

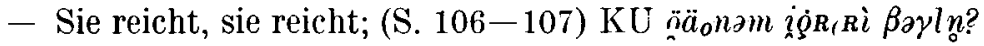

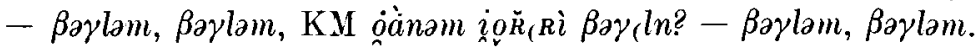
Nimmst du mich zur Gefährtin? - Ich nehme, nehme dich.

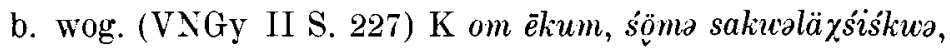
khota oåt khåńśilan? - khåńšilam, khånśsilam. Liebe Elster, weisst du nicht, wo meine Frau steckt? - Ich weiss es, ich weiss es; (IV S. 380 dreimal) vuj-ańšu $\chi \hat{\imath}^{\gamma}$ oåt jälas? - jälas, jälas. Ging hier kein "Tiergreis" vorüber? - Er ging, er ging. 
d. wog. (IV S. 375) nån loåttän: kiske-äkińš lo-voånt voånəp$t i \cdot w a$ ! - loåtti wa, loåtti wa! Ihr sollt sagen: wir treiben das Gestüt des Onkels der Katze! - Wir werden (so) sagen, wir werden (so) sagen.

Vom Standpunkt der ungarischen Sprache ist die folgende Antwort sehr interessant: (WVd I S. 83) LO am pältum ii $\beta$ $\beta^{a} n$ ? - am minèym. Kommst du zu mir (mich heiraten)? Ich komme.

Auch der folgende Fall erinnert an eine ungarische Art der Antwort: (WVd II S. 408-409) KU nä $\gamma$ pälan $\chi \beta \hat{a}$ is ōln mänt

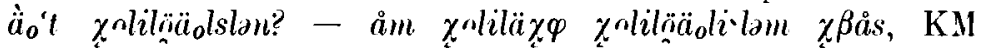

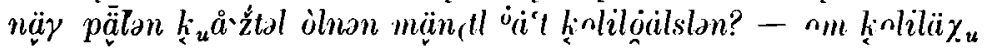

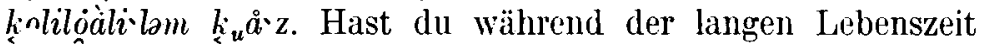
deiner Ohren nicht gehört? - Hören habe ich es wohl gehört. Vgl. hierzu ung. hallani hallottam.

Und hier noch einige Beispiele von Fällen, wo nicht das Verbum wiederholt wird: wog. (VNGy II S. 24) N akim-ājikä

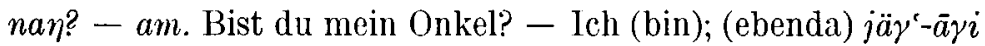

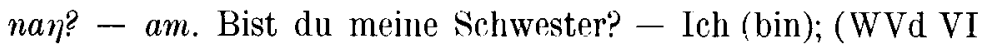

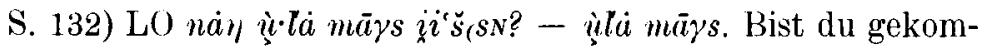
men um Feuer zu holen? - Un Feuer zu holen | (III S. 100

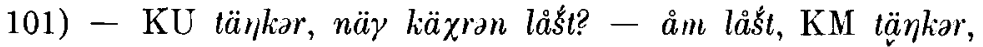

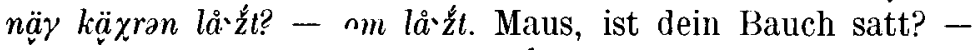

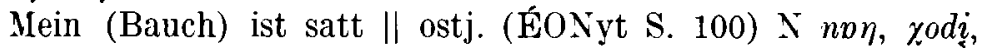

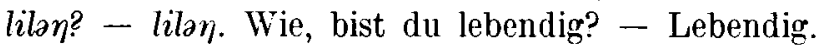

Hierher gehört auch ein Fall, wo nicht das gleiche Verbum wiederholt wird. Es handelt sich um das wogulische Verbum 'habro', dem in der Antwort 'sum' entspricht: (WVd I, 81) LO šriăi óńsi? - òli. Hat er ein Schwert? - Ja ('es ist'). Es muss jedoch bemerkt werden, dass eine solche Antwort die Ausnahme bildet. In mehreren vorhandenen Belegen wird das Verbum 'habeo' wiederholt.

Auch im Wogulischen gibt es Verbalpräfixe wie im Ungarischen, doch verhalten sie sich in den Antworten ganz anders als im Ungarischen. Bei einer kurzen Antwort bleibt im Ungarischen das Verbum weg, während das Präfix das gesamte Zeitwort ersetzt. Im Wogulischen wiederum wird gewöhnlich das Präfix in der Antwort weggelassen:

a. wog. (Man mojtanuv S. 38-39) Kankan ojkan jot-oli? - 
Oli. Ist dein Onkel mit dir? - Er ist / (WVd II S. 406-407)

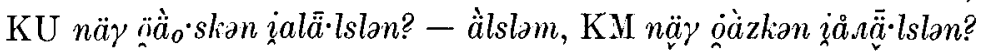
- ă $l s l a m$. Hast du den Teufel getötet? - Ich habe ihn getötet;

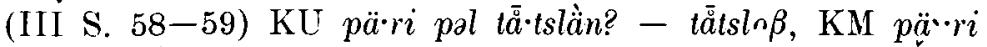
pal tå. slụ̈n? - tå-tsln $\beta$. Habt ihr ihn denn auch zurückgebracht? - Wir haben ihn (zurück)gebracht.

d. wog. (II S. 278-79) KU ma·nn e.l! - mə•nà̀m, ma:nàm!

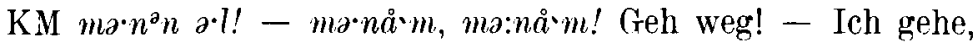
ich gehe!

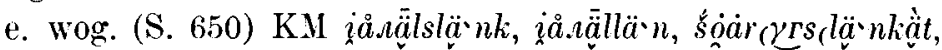

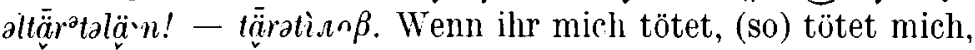
wenn ihr euch meiner erbarmt, (so) lasst mich frei! - Wir lassen dich frei.

Diese Gruppe ist die zweitgrösste und umfasst 57 Beispiele bzw. $21 \%$. Die vorhergehende und diese Art bilden gemeinsam $46 \%$ des Materials.

4. Ein sehr beliebter Typus ist im Obugrischen eine formal verneinende Gegenfrage oder eine von gegensätzlicher Bedeutung, die jedoch einen positiven sinn hat. Natürlich ist diese Art auch in anderen Sprachen, nicht nur in den fimmischugrischen bekannt.

Mir stand keine Statistik von anderen Sprachen zur Verfügung, doch ist kaum zu glauben, dass diese Art in den europäischen Sprachen ebenso häufig verwendet wird wie im Obugrischen, wo jede fünfte Antwort, $20 \%$, zu dieser Gruppe gehört (52 Beispiele):

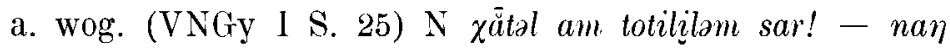

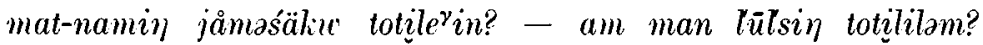
akw'to $\chi$ jåmaśäliw totililam. Ich möchte die Sonne tragen! Wirst du sie wohl gut tragen? - Warum soll ich sie schlecht tragen?! Ich werde sie ebenso gut tragen wie du; (II S. 117)

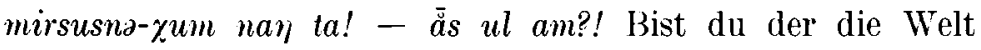
beschauende Mann? - Wie sollte ich es nicht sein? (III S. 117)

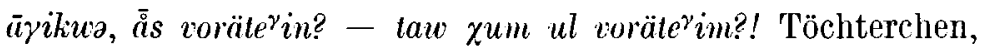
forderst du noch etwas von mir? - Wie sollte ich nicht for-

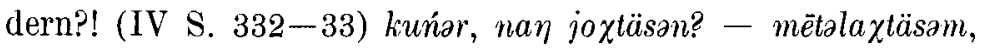
zumla at jozterim?! Bist du, du Armer, gekommen? - Ich habe mich verdingt, wie sollte ich nicht kommen?! (S. 340-41) 


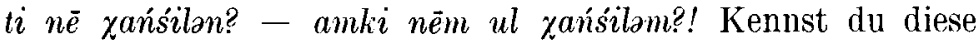
Frau? - Wieso sollte ich meine eigene Frau nicht kennen?!

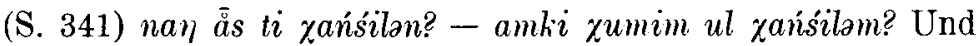
du, kennst dı diesen Mann? - Wie sollte ich meinen eigenen Mann nicht kennen?! - (WVd V S. 103) So mēn iötmén mi$n \bar{e}(\gamma n ?-\dot{o} s \not u \cdot m ? ! m i \cdot n \grave{e} \gamma m$. Gehst du mit uns? - Nun wie denn?! Ich gehe (mit); (S. 113) LO $t i m \bar{a}_{(n n} \ldots$ mat $^{\partial} r \bar{u} \cdot i^{k} \not u l$

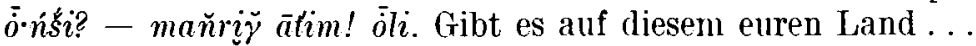
irgendwelche Tiere? - Wie sollte es keine geben! (Ja,) es gibt;

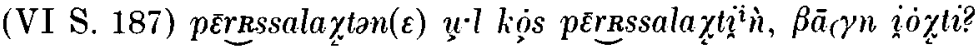

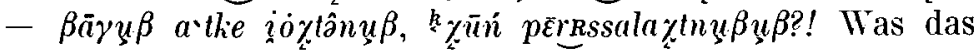
Überfallen betrifft, mögt ihr es ja wohl tun, (aber) reicht eure Kraft aus? - Wenn unsere Kraft nicht ausreichte, wie sollten wir (euch dann) überfallen:! (Man mojtanuv S. 42) N Aman an rovi, ti joralahtunke mos? - Manriy at rori, joralahteken. Ziemt es sich jetzt vielleicht stolz zu sein? - Warum sollte es sich nicht ziemen, sei stolz | (WVd V 179 mehrmals) P men-

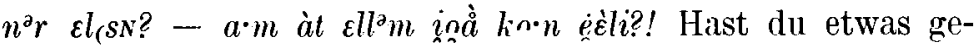
fangen? - (Wenn) ich nichts fange, wer fängt dann (etwas)?!

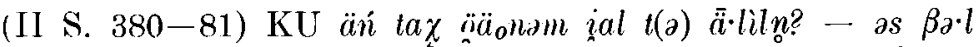

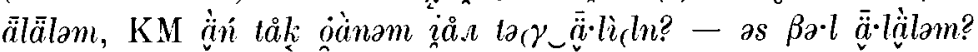
Jetzt wirst du mich wohl dann töten? - Sollte ich dich dann nicht töten? (\$. 388-89) KU ö̈̈onam ial pal t(a) pọnīlan, ia $a \cdot l$

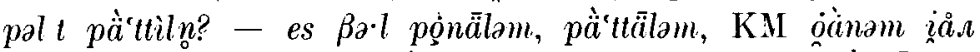

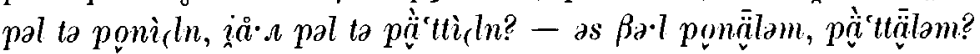
Legst du mich nun unter (dich), fällst du mich num unter (dich)? - Sollte ich denn nicht legen, fallen? (III S. 74-75)

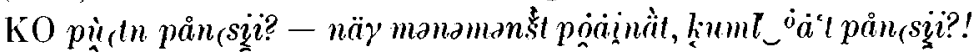
Wird dein Kessel gar? - Er hat seit deinem Fortgehen gekocht, wie sollte er nicht gar sein? (S. 106-107) KU a.m

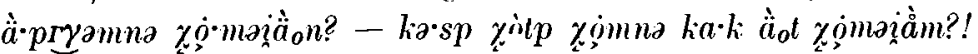

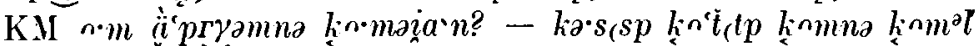
${ }^{\circ} \dot{a}^{c} t$ linmaia ${ }^{\prime} m$ ? ! Verheiratest du dich mit meinem Neffen? Wie würde ich mich nicht mit einem jagenden (und) findenden Mann verheiraten?! (VI S. 122-23 viermal, 124-25 fünfmal)

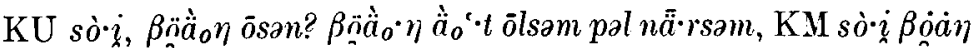

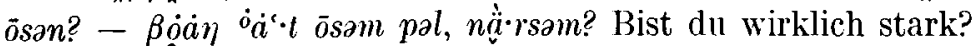
- Wenn ich nicht stark bin, was bin ich (denn)? \| ostj. (AHLQv. 
S. 7) N evi tailen? - malai ant tailem; kat evi tailem. -- Hast du Töchter? - Warum habe ich nicht (warum sollte ich nicht haben); ich habe zwei Töchter; (OH II S. 65-67) śăB(ə)ranən

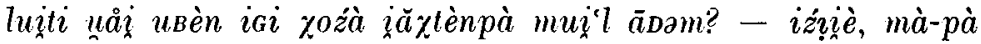
manti zoDi àlt mänlam! Wäre dein Gehen vielleicht schlecht zu deinem alten, mit śănar wie Vogel singenden Schwiegervater? - Brüderlein, wie würde ich nicht gehen! (III S. 148-40 und 152-53) ma jogotti lungteng kattlen uitlen ma jel pemän kunyt jogotten? - näng jastem morting kattlen lungetmän schi täilem alt jogtlem. Weisst ja auch die für meine Ankunft berechneten Tage wie du mir entgegen kommst? - Deine von dir angesagten bemessenen Tage habe ich gezählt, wie sollte ich nicht kommen? I (IO II S. 172-73) jixpoxtan vedem vêr sat' uden-na? - ei under ômsem jixpogenetam sat' kak indam? Dass dir die Brüder getötet sind, tut dir das leid? - Wie sollen mir meine Brüder, die in demselben Mutterleibe gelegen

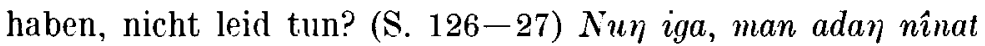
sêmina vêrdem-na, mant nûm-tûrum xujan jina jux tupteta omat tâidan-a? - tisir vêr vêrden-na nuฑat kak ent juxtuptetem. Du Alter, wenn ich euch sehend mache, bist du im Stande mich zu den Männergewässern der oberen Welt bringen? Wenn du solch' eine That vollführst, wie sollte ich dich nicht (dahin) bringen.

b. wog. (Man mojtanuv S. 41) Aman tur-at-jalijen? - Mat kol-ke oli, man manry at jalev. Geht ihr nicht dorthin? - Mag es ein Haus welcher Art immer sein, warum sollten wir nicht

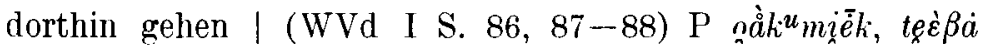
Laspußna mutra a't la kańšseyn? - kum a't kańšeym?! Meine Tante, weisst du nicht ein Zauberkunststück, um ihn zu fangen? - Wie sollte ich nicht wissen?! || ostj. (ÉONyt S. 138) àzi, loua

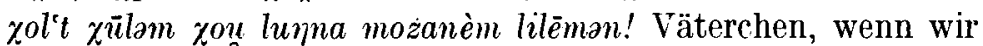
dann einen Knochen-köpfigen grossen Stör fangen werden, werden wir ihn nicht gleich aufessen? - An diesem jämmerlichen Sommer, warum sollten wir ihn nicht essen!

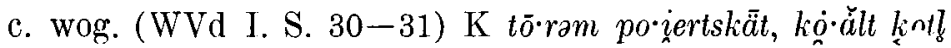

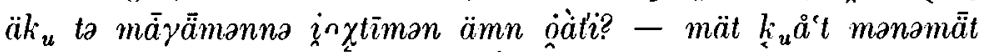

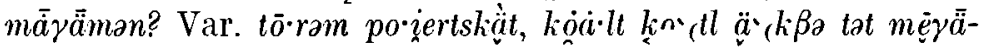




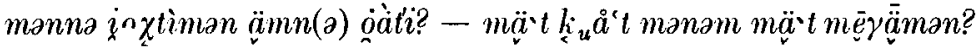
Wenn Crott (es) gestattet, kommen wir am morgigen Tag auf diesen unseren nämlichen Platz, oder nicht? - Was, wohin sollte denn wohl unser Platz gehen? || ostj. (OH II S. 195-97, 232-35, 243) N männlen mui ändom? - mäsejämke alt männlem? Kommst oder nicht? - Wenn man mich hingegeben hat, wie würde ich nicht gehn? (IO II S. 104-105) S tav jisna janxîdem tâidan, metta inda? - Kak en tâidam! Tâbet piś keu pâkripna tolt a sornín-pûnip man tavem. Hast du ein längst zugerittenes Pferd, oder nicht? - Wie soll ich es nicht haben! Hinter sieben steinernen Mauern, da steht mein goldhaariges Ross.

d. wog. (VNGy I S. 9, 9-10, 10) N lāwän: Tari-pēśńnimālä-

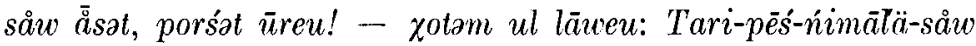

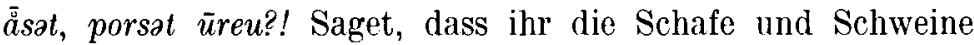
des T. bewachet! - Warum sollten wir nicht sagen, dass wir die Schafe und Schweine des T. bewachen?! (WVd III S. 34)

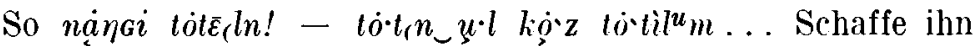
selbst hin! - Wie sollte ich ihn nicht hinschaffen . . .| (S. 167

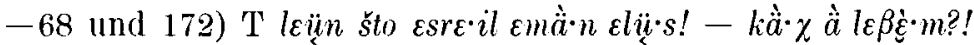
Sage, dass ich den Teufel erschlagen habe! - Wie sollte ich (es) nicht sagen?! (Wie werde ich nicht sagen?!) \| ostj. (OVE I S.

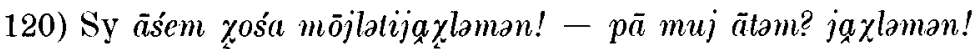
Gehen wir meinen Vater besuchen! - Warum denn nicht? (Was [ist] denn Schlechtes [dabei])? Gehen wir! (S. 136) manam jüš üjatti tuvalng! - jā muj ātan; tūlew jūš üjatti. Nehmt mich mit den Weg zu zeigen! Ja, warum dem nicht (Was [ist denn] da schlecht): wir nehmen dich mit, [uns] den Weg zu zeigen.

f. wog. (Man mojtanuv S. 28) At rori. - Manriy at rovi?! rovi! Es ist nicht gestattet. - Warum ist es nicht gestattet?! es ist gestattet. II ostj. (OVE I S. 136) Sy mā oror lonaln mue' uātman èlapan àmaslam - pā muj àtam; muv wātman èlapan $\bar{s} p s a$. Ich setze mich oben auf das Dach des Verdecks die Landschaft anzusehen. - Warum denn nicht; sitz (dort) oben, die Landschaft anzusehen.

5. Viel kleiner ist die Gruppe, wo die Worte des Fragenden nicht wiederholt werden (28 Fälle bzw. $10 \%$ ). Darin gibt es wiederum verschiedene Stufen. Vielleicht kann nur ein Wort 
wiederholt werden (gewöhnlich das Verb), doch in einer ganz neuen Umgebung. Die Antwort ist bejahend, doch entwickelt sie den Gedanken gleichzeitig weiter, der Antwortende macht zusätzliche Angaben. Hierfür ein paar Beispiele:

a. wog. (WVd II S. 286-87) KU $\ddot{a}_{o} \cdot n \dot{s} \chi_{\varphi}$ mä:tar $\chi^{\circ} n t s$,

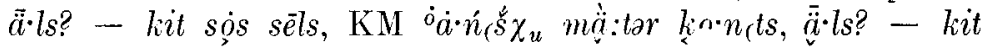
sos sẹels. Hat der Mann etwas gefunden (und) erlegt? - Er hat zwei Elentiere erbeutet; (S. 498-99) KU màtsar mär $\chi_{-}$

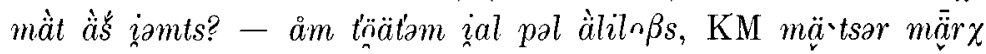

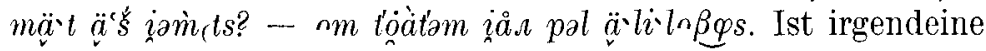
schwere Sache geschehen? - Mein Vater ist getötet worden;

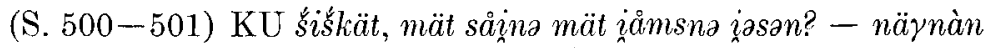

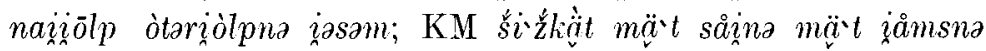

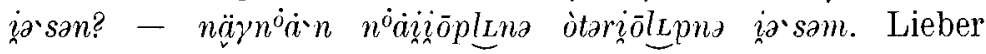
Junge, bist du wegen irgendeiner guten Sache gekommen? Ich bin um Fürstinnenhilfe, Fürstenhilfe gekommcn; (S. 652

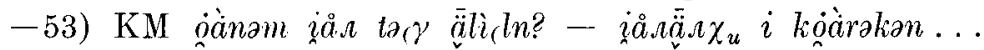
Tötest du mich nun? -- Du musst wohl getötet werden; (VI

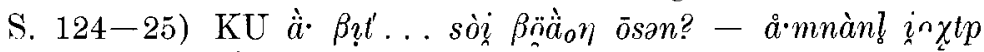

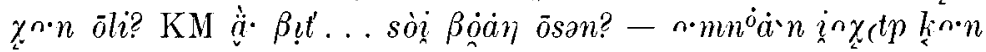
ódii? He Wasser . . . bist du wirklich stark? - Wer ist da,

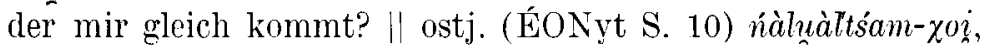

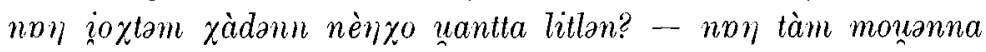

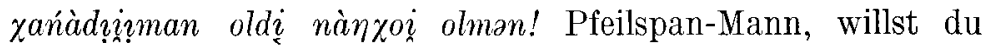
im Haus, wohin du ankommst, einen Menschen sehen? - Du bist ein auf deiner Erde geheim lebender Mann; (S. 93) nvn

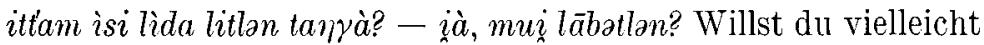
etwas essen? - Nun, was gibst du zu essen?

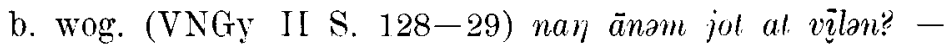
alim-ās, minimèn! Möchtest du mich mitnehmen? - Onkel,

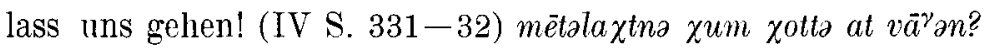
- au zum am $t i$... Kennst du nicht irgendjemanden, der zu mir als Diener käme? - Ich bin hier als ein solcher | (S. 382) K omnana oåt khomijan? - taśna ulýam. Heiratest du mich? -

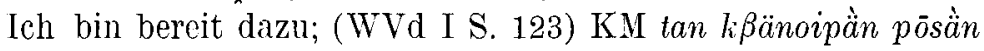
le a't jamtili? - åipàt $t$. Kommt nicht die Zeit ihrer Befreiung?

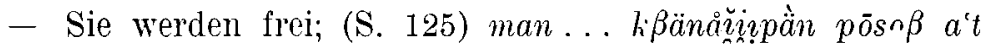
jamti? - nan . . a åñ îipina. Kommt nicht . . die Zeit unserer 
Befreiung? - Ihr . . werdet frei werden; (II S. 36-37) $\mathrm{KU}$

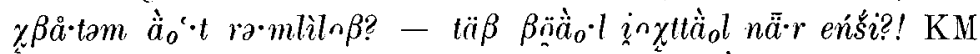

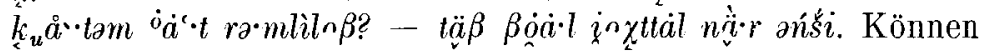
wir ihn (wohl) nicht irgendwie in unsere Hände bekommen? Was hat er (denn), was man nicht mit Stärke besiegen könnte?!

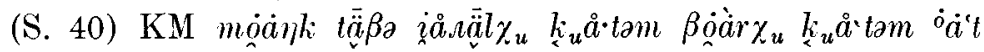

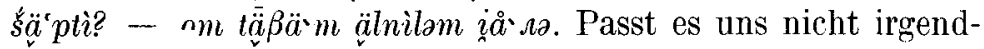
wie, ihn zu töten? - Ich würde ihn töten; (S. 286-87) $\mathrm{KU}$

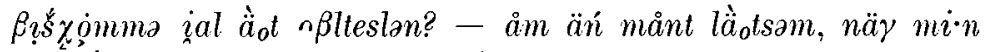

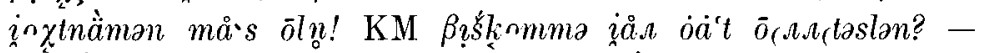

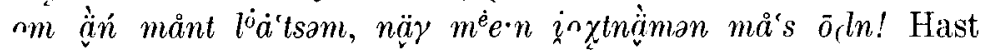
du dem Jungen nicht gesagt, dass er warten soll? - Ich sagte eben, bleibe du da, bis wir kommen! (S. 288-89 und 298-99)

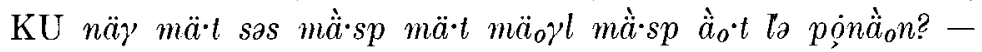

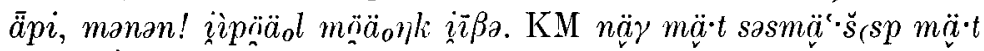

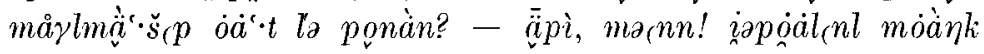
iì $\beta \beta$ ! Würdest du nicht irgendeine Rückenhilfe, irgendeine Brusthilfe geben? - Junge geh! wir kommen nach! (S. 344-45)

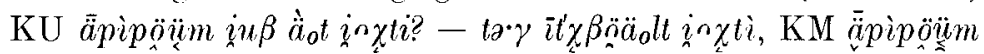

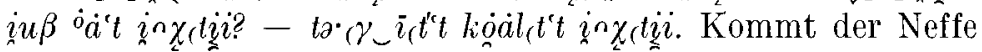
nicht nach Hause? - Er kommt heute Abend (oder) am Mor-

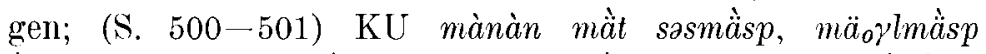

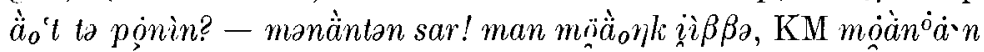

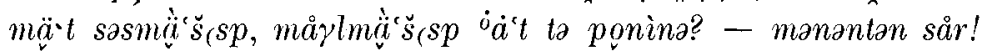

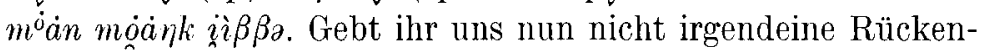
stütze, Bruststütze? - Geh du nur! Wir selbst kommen (schon) $\|$ ostj. (IO II S. 152-53) S tada, munat et partten-li nê $\eta \hat{e} t-$ tâtta, xui êttîtta? - jânxada. Väterchen, gestattest du uns nicht, Frauen und Männer uns anzusehen? - Geht.

c. wog. (VNGy III S. 523-25) P viir puiip tipkharkhi,

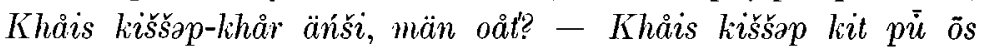
$\bar{o} l i \gamma$, ti vōôt ólsei. Specht mit rotem Gesäss, hat Khais jemanden, der ihn sucht, oder hat er keinen? - Es gibt zwei Khais suchende Jünglinge, sie sind schon nicht mehr weit; (IV S. 312-13) LM ta nuฑan unalpä tul-šup nåui män oåt? - ta

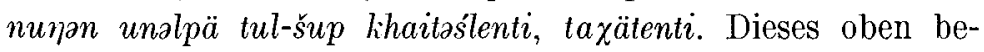
findliche Wolken-Stückchen bewegt sich, oder nicht? - Dieses oben befindliche Wolken-Stückchen zieht schnell, es schwebt 


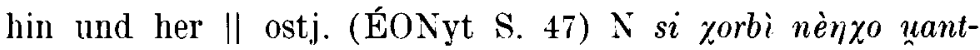
sàdị, mola andàm? - tùlizat pilna manmal-lamba. - Habt ihr solchen Mann gesehen, oder nicht? - Er ist wahrscheinlich mit den Gänsen fortgegangen | (IO II S. 106-107) $\hat{E} v a t u$ tâit-ta, metta en tâit? - xûdem êra tâit. Hat er eine Tochter oder hat er keine? - Er hat drei Töchter.

d. wog. (Man mojtanuv S. 29) Mankvla, manar vareyən?

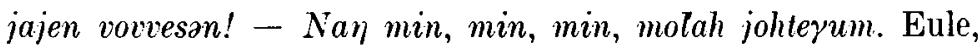
was machst du? Komm, du wirst gerufen! - Geh nur, geh nur, geh nur, ich komme auch bald $\|$ ostj. (ÉONyt S. 23) N Titlan-ki,

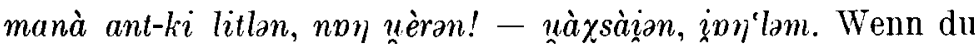
willst, gehe, wenn du nicht willst, das ist deine Sache! - Man luft mich, ich gehe ( (IO II S. 154-55) tada, xûdem xui munat ei xôtîvet nêyat veje! - nịa ajetta nề jâxtam, veden. Väterchen, uns drei Männern nimm Frauen aus einem Hause! - Die Frauen, die ihr selbst gefunden habt, geh ich und nehme.

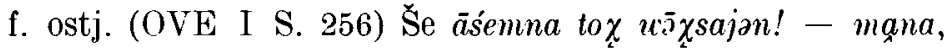

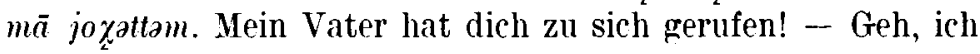
komme.

6. Zur letzten Gruppe gehören jene Antworten, die aus dem einen oder anderen Grund nicht unbedingt bejahend sind. Hier bilden sich gleichsam von selbst drei Untergruppen: die beschränkende, die bedingende und die ausweichende Antwort.

Beispiele für eine beschränkende Antwort:

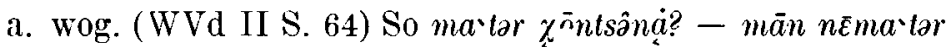

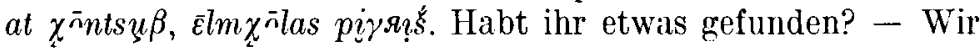
haben nichts gefunden, (ausser) einem Menschensöhnchen. (VNGy IV S. 383-84) K nåmtan päti? - mäta lul oåtí. Gefällt sie dir? - Sie ist nicht hässlich; (WVd II S. 344-45) KU

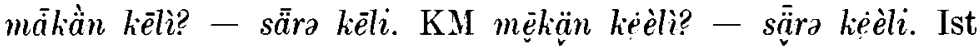
die Erdoberfläche sichtbar? - Sie ist kaum sichtbar. I (VNGy

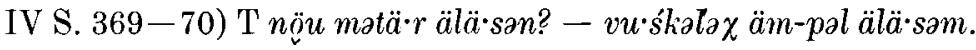
Hast du etwas gefangen? Ein wenig habe ich auch gefangen;

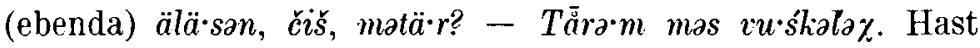
du, mein Lieber, etwas gefangen? - Gott hat mir ein wenig

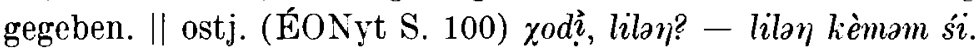
Wieso, lebst du noch? - Ich lebe kaum.

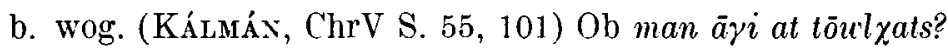




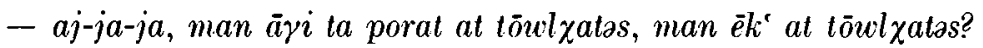

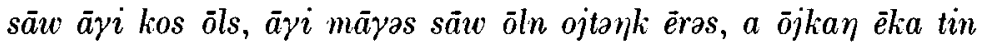
at ōñsəs. Gab es denn nicht Mädchen genug? - Hei, gab es damals Mädchen oder Frauen nicht genug? Wohl gab es viele Mädchen damals: für ein Mädchen hatte man aber viel zu zahlen, während die verheiratete Frau nichts kostete.

c. ost.j. (IO II S. 166-67) S munat mettejat mededen, metta innda? - ć̂́mdat medeu. Werdet ihr uns etwas geben oder nicht? - Etwas werden wir euch geben.

Bedingende Antworten:

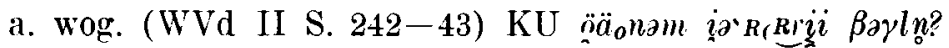

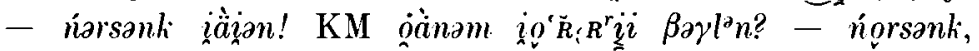
iäajzan! Nimmst du mich zum Gefährten? - Wenn du willst,

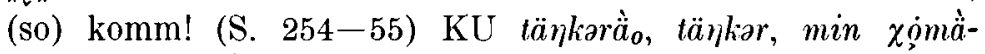

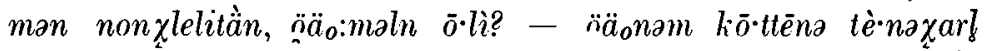

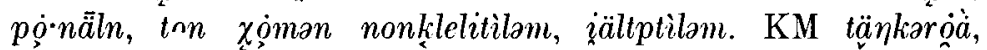

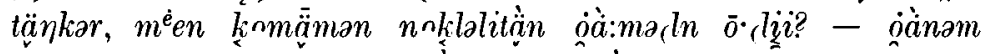

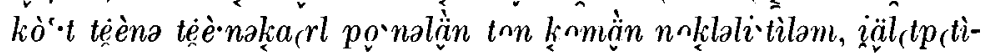
lam. Maus, Maus, kannst dı unseren Mann zum Leben erwecken? - Beschafft mir Nahrung für ein Jahr, dann werde ich euren Mann zum Leben erwecken (und) heilen. (S. 448-49)

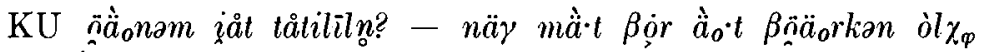

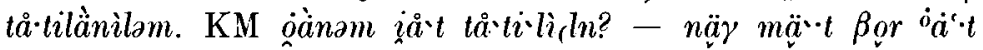

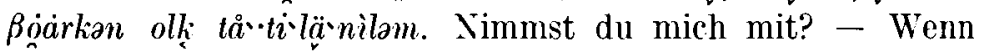
du nichts Unschickliches machtest, würde ich dich (wohl) mit-

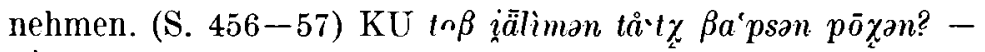

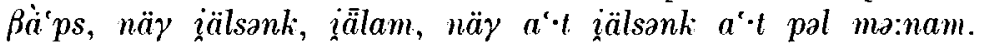

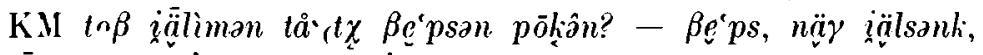

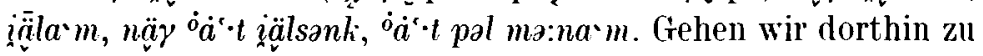
jenem deinem anderen Schwiegersohn? - Schwiegersohn, wenn du gehst, gehe ich (auch) hin, wenn du nicht gehst, gehe ich auch nicht hin. I (VNGy IV S. 359) T šerka·s, poso• $\eta$ tẩ.raman

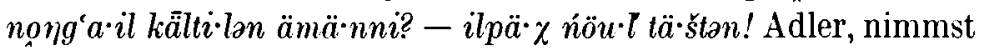
du mich in die lichte Welt hinauf? - Bereite mehr Fleisch!

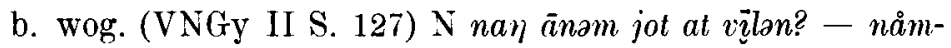
ton-ke ăli, manaräig at taji?! Möchtest du mich nicht mit dir nehmen? - Wenn du Lust dazu hast, warum könnte man es nicht machen?! 


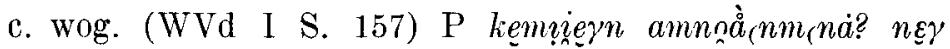

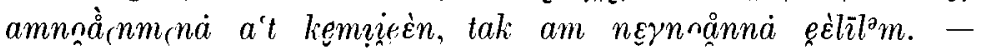

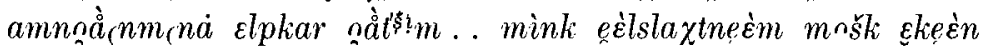
keminaxtima! Verheiratest du dich mit mir? (Wenn) du dich nicht mit mir verheiratest, so töte ich dich. - Einen, der mich tötet, gibt es nicht... (A ber) statt dass wir einander töteten, lass uns heiraten. $\|$ ostj. (ONGy S. 184) N naj zośa pā jaqlen,

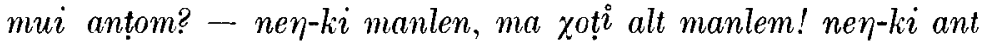
manlen, ma śirtn' zoltśa manlem? Zur Fürstenmaid gehst du hin oder nicht? - Wenn du gehen willst, wie würd' ich denn nicht auch gehen! Wenn du nicht gehst, wohin würde ich denn wohl gehen?

d. wog. (WVd II S. 454-55) K om pō žamn pal îấln! - $\dot{a} \dot{a}$

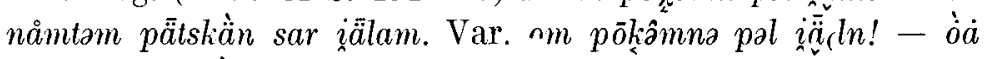
nåmtam pạ̈tskä̀t sår i iäla'm. Komm gleichzeitig auch zu mir! Ja, wenn ich Lust haben werde, komme ich schon.

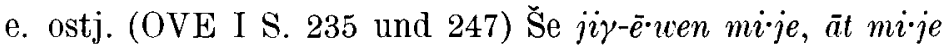

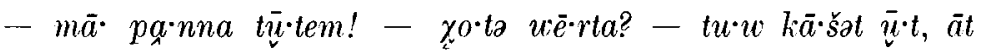
ma.nət! Gib [mir] deine Schwester, gib [mir] sie nicht - ich nehme sie mit! - Was soll ich machen? (Wie machen?) Wenn sie Lust hat (Ihre Lust ist), soll sie gehen!

f. ostj. (AHLQv. S. 13-14) N aśa, ma pa mantem. - xun manten, mana. Vater, ich gehe auch (mit). - Wenn du gehst, so gehe. (OVE I S. 164) Sy mā āpśem olt(i) taxza mã lēśatlem. - léśat mol wèren ūl ki, léśati! Die Schlafstelle meines Bruders werde ich bereiten. - Wenn du sie bereiten musst (wenn deine bereitende Sache ist), bereite sie!

Die ausweichenden Antworten sind eine Zwischenform zwischen positiver und negativer Antwort. Sehr diplomatisch ist z.B. folgende Erwiderung: wog. (VNGy IV, 340) $\mathrm{N}$ āyin-

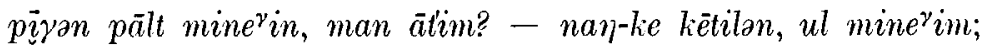

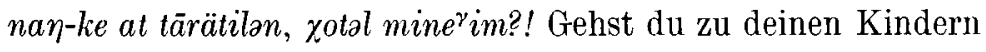
oder gehst du nicht? - Wenn du mich schickst, wie sollte ich nicht gehen; wenn du mich nicht gehen lässt, wie sollte ich dann gehen?!

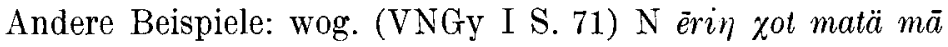
$v \bar{a}^{\gamma} \partial n ?-v \bar{a} k e u w$ èrt, yotal läpijin tü? Weisst du vielleicht irgendwo einen entsprechenden Ort? - Wenn wir auch wüssten, 
wie hättet ihr dort Platz? (IV S. 31) äśan męlan man at? am mîtalam zot kūsaj? ti kwolt kūsaj am ti-pal. Gibst du mir deine Schwester oder nicht? - Wenn ich sie nicht gäbe, wo gibt es denn hier noch einen Wirt? In diesem Haus bin ich

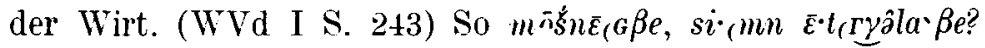

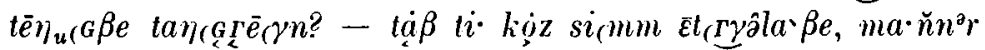
nli?! Moś-Frauchen, hast du Hunger? Möchtest du essen? Wie ich auch Hunger habe, was gibt es zu essen?! (S. 42-45)

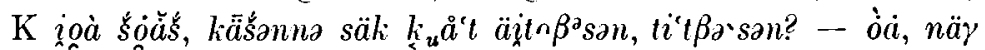

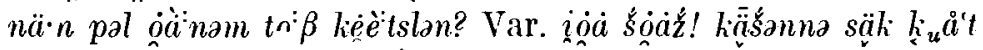

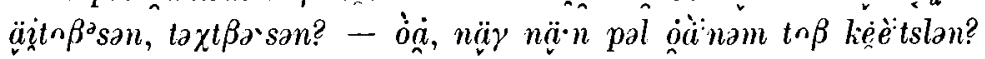
Nun Sohn, hat dir dein jüngerer Bruder vielleicht viel zu trinken (und) zu essen gegeben? - Ja, wozu hast du mich denn auch dorthin geschickt? (II S. 252-53) KU nåmtan päti? $-\ddot{a} \cdot k_{u} t \curvearrowright n n \bar{e}$ ! KM naimtan päti? $\ddot{a} \cdot k_{u} t n n$ nèrè! Gefällt sie dir? - Eine Frau wie die andere! (Die Antwort ist jedoch positiv, denn der Held heiratet das gleiche Mädchen.)

Diese Gruppe ist beinahe so gross wie die vorhergehende: sie umfasst 27 Fälle bzw. $10 \%$.

Alle erwähnten Typen von Antworten treten sowohl im Wogulischen als auch im Ostjakischen auf. Auch ist ihre prozentuale Aufteilung in den diversen Dialekten ungefähr gleich. Es mag ein blosser Zufall sein, dass von den insgesamt zehn westwogulischen Antworten in keiner die ganze Frage wiederholt wurde und dass die Prozentzahl von Gegenfragen im gleichen Dialekt im Vergleich zu den anderen das Doppelte beträgt.

Die Überprüfung dieses geringen Details hat, so hoffe ich, die Kenntnis über die gemeinsamen Züge der Syntax der finnisch-ugrischen Sprachen weiter bereichert.

Béla Kálmáx 